\title{
Que desafios e Possibilidades Expressam os Licenciandos que Começam a Aprender sobre Ensino de Ciências por Investigação? Tensões entre Visões de Ensino Centradas no Professor e no Estudante
}

\section{What challenges and possibilities do pre-service teachers who begin to learn about teaching science as inquiry express? Tensions between a teacher-centered and a student-centered view of teaching}

\section{Natália Ferreira Campos Daniela Lopes Scarpa

Neste estudo, apresentamos as concepções que estudantes de Ciências Biológicas expressam em escritos reflexivos sobre as possibilidades e desafios do Ensino de Ciências por Investigação (EnCI), após os primeiros contatos com essa abordagem em uma disciplina do curso de licenciatura. Conhecimentos, crenças e concepções dos professores influenciam sua prática profissional. Conhecer as concepções dos licenciandos sobre EnCI é importante para compreendermos o que pode inibi-los de adotar essa abordagem, trazendo implicações para os processos de formação docente. Foi realizada a análise de conteúdo de escritos reflexivos de 46 licenciandos. Os dados apontam que os licenciandos reconheceram satisfatoriamente as principais qualidades do EnCI relacionadas ao conhecimento pedagógico e ao conhecimento do tema. Os desafios citados relacionam-se principalmente ao conhecimento pedagógico. Foi possível identificar concepções limitantes ao uso do EnCI que se relacionam em parte à falta de experiência em ensino, esperada para esse estágio de formação e, em parte, a mitos culturais e tensões entre uma visão de ensino tradicional, centrada no professor, e uma visão de ensino centrada no estudante. Tornar as concepções explícitas e analisálas profundamente junto aos professores em formação pode ser um passo inicial na desconstrução das concepções limitantes.

Palavras-chave: ensino de ciências por investigação; ensino de biologia; conhecimento dos professores; formação de professores.

In this study we present pre-service biology teachers' conceptions about the possibilities and challenges of teaching science as inquiry, after their first lessons about this approach in teacher education course. Teachers' knowledge, beliefs and conceptions have a relevant impact on professional performance. Knowing the conceptions of pre-service 
teachers is relevant to understand what can inhibit them from adopting this approach, bringing implications to the processes of teacher education. The content analysis of 46 reflective writings was carried out. The data indicate that the pre-service teachers have satisfactorily recognized the main qualities of teaching science as inquiry related to pedagogical knowledge and subject-matter knowledge. The challenges reported are mainly related to pedagogical knowledge and it has been possible to identify conceptions limiting the use of the inquiry approach. These conceptions refer partly to the lack of teaching experience - somehing expected for this stage of teacher education -, partly to cultural myths and tensions between a traditional, teacher-centered view of teaching and a student-centered view of teaching. Making explicit these conceptions and analyzing them deeply with the pre-service teachers could be an initial step in deconstructing the limiting conceptions.

Keywords: inquiry-based science education; pre-service teachers; teacher knowledge; pre-service training.

\section{Introdução}

O que os professores sabem sobre Ensino de Ciências por Investigação (EnCI)? Um estudo revelou que a porcentagem média de tempo que professores da educação básica estadunidenses declararam dedicar em sala de aula ao EnCI foi de 38,7\% (Marshall, Horton, Igo, \& Switzer, 2009). Essa porcentagem, considerada alta, parece incongruente com os inúmeros desafios de aplicação do EnCI reportados pela literatura (Capps, Crawford, \& Constas, 2012). Esse contraste intrigou um grupo de pesquisadores que, a partir dos resultados de uma pesquisa do tipo survey, concluíram que apesar de muitos professores acreditarem realizar atividades investigativas com certa frequência, poucos têm um conhecimento bem estruturado sobre o EnCI (Capps, Shemwell, \& Young, 2016).

Considerando o contexto de um país que tem tido a investigação e as práticas científicas como prioridade nas reformas curriculares do ensino de ciências das últimas décadas (Minner, Levy, \& Century, 2010; National Research Council, 2000, 2012), esse dado pode ser considerado surpreendente, indicando o tamanho do desafio que os professores enfrentam para se apropriarem dessa abordagem de ensino.

No Brasil, apesar de não haver diretrizes específicas para essa abordagem, os Parâmetros Curriculares Nacionais (MEC, 1998) já incorporavam, dentre os objetivos para o ensino de ciências, habilidades relacionadas a práticas científicas como "formular questões" e "saber combinar leituras, observações, experimentações e registros para coleta, comparação entre explicações, organização, comunicação e discussão de fatos e informações" (p. 33). Porém, pesquisadores ainda apontam o caráter descritivo, memorístico e descontextualizado do ensino de ciências escolar (e.g., Krasilchik, 2004; Munford, \& Lima, 2007; Scarpa, \& Silva, 2013).

$\mathrm{O}$ EnCI é uma tendência no ensino de ciências, tanto em termos de reformas 
curriculares como em termos de pesquisa nessa área (Abd-El-Khalick et al., 2004; Pedaste et al., 2015). No Brasil, o interesse por essa abordagem é crescente, tendo como evidência o Encontro de Ensino de Ciências por Investigação ocorrido São Paulo em maio de 2017 que contou com 507 inscritos e mais de 200 trabalhos apresentados (http:// www.veradata.com.br/eneci/?q=node/252).

Dado que o EnCI expressa uma abordagem privilegiada para a alfabetização científica dos indivíduos, que inclui a aprendizagem sobre conteúdos conceituais, sobre habilidades envolvidas no fazer científico, sobre natureza da ciência, além de possibilitar o trabalho com a linguagem argumentativa (Scarpa, Sasseron, \& Silva, 2017) temos na formação de professores um caminho fundamental para que se promova qualquer mudança no cenário educacional. Isso nos leva a questionarmos como a formação de professores de ciências no Brasil tem incorporado essa tendência global.

A base de conhecimentos profissionais da docência tem sido explorada, modelada e avaliada na sua influência sobre a prática docente (Gess-Newsome \& Lederman, 1999; Shulman, 1987; Tardif, 2012). Para o exercício da docência, o professor deve desenvolver diferentes dimensões do conhecimento, como o conhecimento pedagógico geral, o conhecimento do conteúdo a ser ensinado, o conhecimento pedagógico do conteúdo, do contexto, dos aprendizes, entre outros (Shulman, 1987). Cada uma dessas dimensões influencia a atuação docente (Crawford \& Capps, 2016). Além disso, as concepções que os professores apresentam sobre ciência, seus estudantes e sobre as práticas pedagógicas influenciam se e quanto esse professor utilizará em suas aulas a abordagem do EnCI (Lotter, Harwood, \& Bonner, 2007). Portanto, compreender quais são esses conhecimentos, crenças e concepções, como se desenvolvem e como cada uma dessas dimensões influencia a prática docente é essencial para aprimorarmos o conhecimento sobre aprendizagem e formação de professores.

Neste trabalho, foram investigadas as concepções sobre as possibilidades e os desafios do EnCI, apresentadas por licenciandos de Ciências Biológicas em reflexões escritas, após uma sequência de aulas focada nessa abordagem. Mapear os desafios e dilemas que os professores enfrentam ao pensar e atuar na perspectiva do EnCI é importante para entendermos o que inibe os professores de adotarem essa abordagem. Avaliar como os professores em formação desenvolvem e compreendem as diferentes dimensões do seu conhecimento relacionadas ao EnCI é um passo fundamental na compreensão desse processo de aprendizagem e desenvolvimento profissional.

\section{Os desafios de ensinar ciências por investigação}

Para que os futuros professores tenham uma concepção mais informada de EnCI e consigam superar os desafios de praticar essa abordagem, precisamos aprimorar nossa compreensão do processo de formação de professores. Buscando entender a profissão docente, alguns autores discutem sobre o que seria a base de conhecimento profissional docente (Fernandez, 2015; Shulman, 1987; Tardif, 2012). Shulman (1987) descreve sete categorias que compõem a prática docente: conhecimento do conteúdo; conhecimento 
pedagógico geral; conhecimento do currículo; conhecimento pedagógico do conteúdo; conhecimento dos estudantes e suas características; conhecimento do contexto educacional; conhecimento dos fins educativos; e conhecimento dos propósitos, valores e fundamentos filosóficos e históricos. Essas dimensões do conhecimento docente têm sido exploradas e modeladas na busca por compreender a complexidade da formação e desenvolvimento das habilidades educacionais (e.g., Berry, Friedrichsen, \& Loughran, 2015; Fernandez, 2015; Helms, \& Stokes, 2013).

Assim como os conhecimentos, as crenças e concepções dos professores também influenciam sua prática profissional (Lotter et al., 2007). Epistemologicamente, crenças e conhecimentos são entidades diferentes, mas na prática e no discurso dos professores raramente são distinguíveis. Para Tardif (2012), o saber profissional é constituído "na confluência entre várias fontes de saberes provenientes da história de vida individual, da sociedade e da instituição escolar, dos outros atores formativos, dos lugares de formação, etc." (p.64). Assim, antes de ser professor o indivíduo constrói conhecimentos, competências, crenças e valores que são "reatualizados e reutilizados, de maneira não reflexiva, mas com grande convicção, na prática de seu ofício" (Tardif, 2012, p.72). Segundo esse autor, os professores têm concepções sobre sua prática, a respeito dos estudantes, da gestão e das formas de ensinar, mas essas concepções não são baseadas em um esforço de totalização e unificação com critérios de coerência. Então, o professor não possui uma única concepção, mas várias concepções que utiliza em sua prática em função das suas necessidades e limitações (Tardif, 2012). Essas concepções apresentam um impacto substancial nas escolhas docentes e na prática do EnCI (Lotter et al., 2007; Roehrig, \& Luft, 2004).

O EnCI, segundo Krämer et al. (2015), é reconhecido na literatura por promover o entendimento conceitual, o pensamento crítico e uma atitude positiva em relação à ciência, assim como elevar a motivação e o interesse dos estudantes. Apesar disso, a maioria dos estudos tem apontado a pouca presença do EnCI na sala de aula e os muitos desafios e dilemas que os professores enfrentam ao tentar trazer essa abordagem para sua prática (Krämer et al., 2015). Apesar da grande divulgação do EnCI, poucos documentos oferecem definições e formas de operacionalizar essa abordagem (Borda Carulla, 2012; Capps et al., 2016) o que pode ter gerado concepções equivocadas e incompreensões por parte dos docentes.

Entender o Ensino de Ciências por Investigação como uma abordagem de ensino implica em reconhecer que o EnCI não é só uma forma de ensinar, que pode fazer uso de uma gama de estratégias, mas que ele se fundamenta sobre um conjunto de pressupostos e atende a determinados objetivos de aprendizagem. Os pressupostos socioconstrutivistas que alicerçam o EnCI colocam-no em acordo com uma visão de ensino e aprendizagem centrada no estudante, que privilegia o desenvolvimento da autonomia e da autorregulação do aprendizado, que leva em consideração os conhecimentos prévios dos indivíduos, que favorece o desenvolvimento da linguagem, do trabalho em grupo e da interação social como fonte de aprendizagem e de construção 
conjunta do conhecimento, e que assume a perspectiva da avaliação formativa e a valorização do erro como parte do processo de aprender (Carvalho, 2013; Minner et al., 2010; Sasseron, 2015). Visualizar um ensino que concretize esses princípios é bastante desafiador para a maioria dos professores (Windschitl, 2002).

Em relação aos objetivos do EnCI, além da aprendizagem dos conteúdos conceituais e factuais das ciências, ele tem como objetivo de aprendizagem intrínseco o desenvolvimento de habilidades relacionadas às práticas científicas, incluindo a dimensão cognitiva de raciocínio lógico e científico, como a interpretação de dados e a reflexão para a produção de conclusões e explicações baseadas em evidências, assim como a argumentação (Krämer et al., 2015; Minner et al., 2010; Pedaste et al., 2015; van Uum, Verhoeff, \& Peeters, 2016). É importante ressaltar que esse conjunto de habilidades ultrapassa em muito a mera ação manipulativa, já que a associação direta com atividades práticas ou experimentais está entre as concepções docentes sobre EnCI consideradas equivocadas (Munford, \& Lima, 2007; National Research Council, 2000). Atividades práticas que se baseiam em seguir protocolos fechados e descontextualizados, que não oferecem suporte para nenhuma das características essenciais do EnCI, nem engajamento intelectual do estudante em nenhuma fase do ciclo investigativo, não podem ser consideradas investigativas. Além disso, a experimentação não é a única forma de gerar dados. Outras metodologias como a modelagem ou o método observacionalcomparativo são formas igualmente válidas (Scarpa, \& Silva, 2013).

Ainda, o EnCI é especialmente interessante para discutir aspectos de natureza da ciência (NdC), possibilitando a compreensão do processo de produção de conhecimento científico como um empreendimento social em que diversos métodos são colocados em prática de forma criativa e mutável ao longo do tempo e de acordo com as ferramentas disponíveis (Sandoval, 2005). As pesquisas sugerem que o modelo de ciência que os professores experimentaram ao longo de sua formação podem influenciar negativamente seus esforços para praticar o EnCI (Lotter, Smiley, Thompson, \& Dickenson, 2016). Avaliando 14 professores de ciências iniciantes durante um ano, Roehrig e Luft (2004) mostraram que tanto uma visão contemporânea de $\mathrm{NdC}$, quanto uma visão de ensino orientada ao estudante são cruciais na implementação do EnCI.

Sendo assim, os professores que desejam colocar em curso a abordagem do EnCI precisam ter uma compreensão estruturada de elementos pedagógicos relacionados a como os indivíduos aprendem e ao tipo de estratégia didática mais adequada, assim como de elementos do próprio conteúdo científico e das práticas envolvidas na ciência, buscando contemplar desta forma os objetivos conceituais, epistêmicos e sociais do ensino de ciências (Duschl, 2008; Kelly, 2014). Dentre os desafios para o EnCI considerados por Kelly (2014) estão incluir na prática esses três objetivos, especialmente ensinar como se engajar nas práticas científicas e como fazer julgamentos epistêmicos, ou seja, julgar a confiança e validade das afirmações.

Para engajar os estudantes em práticas investigativas autênticas, o processo investigativo pode ser dividido em unidades menores que irão guiar a atenção dos 
estudantes para características específicas do pensamento científico. Essas unidades podem ser compreendidas como fases do ciclo investigativo (Pedaste et al., 2015). Buscando pelos elementos-chave do EnCI, Pedaste et al. (2015) realizaram uma revisão sistemática da literatura a partir da qual produziram uma síntese, combinando os pontos fortes dos modelos de EnCI propostos até aquele momento, que expressa o delineamento de um ciclo investigativo. A síntese apresentada pelos autores é composta de cinco fases, que podem incluir subfases e está descrita na Figura 1.

Nessa síntese, chama atenção a fase de Orientação, que contempla a dimensão pedagógica de engajamento dos estudantes, momento em que há a motivação em relação a um tópico e o estabelecimento de um problema que servirá como desafio de aprendizagem para os estudantes. Também ressaltamos o destaque para a subfase de Exploração, que deixa explícita que a Experimentação não é o único meio de gerar dados para responder a uma questão de investigação, solucionar um problema ou construir uma explicação. No modelo descrito por Pedaste et al. (2015) não há uma sequência pré-definida das fases. Embora na maioria dos artigos revisados o ciclo se inicie pela fase de Orientação, o percurso ao longo das atividades pode ser variado. A fase de Discussão, que inclui as subfases de Comunicação e Reflexão, está relacionada à qualidade da aprendizagem e à regulação do processo e pode ocorrer para todo o ciclo ou para cada fase separadamente.

Um ponto de debate em relação ao uso de atividades investigativas é a quantidade de direcionamento do professor. Muitos professores acreditam equivocadamente que o EnCI consiste em deixar o estudante desenhar e executar investigações científicas do início ao fim por si próprios (Banchi, \& Bell, 2008). Entretanto, o EnCI suporta diferentes graus de abertura aos estudantes, desde atividades mais estruturadas onde o professor fornece a questão científica e os procedimentos de obtenção de dados, até atividades mais abertas onde os estudantes são responsáveis por todas as etapas da investigação (Banchi, \& Bell, 2008). No entanto, ressalta-se que mesmo em atividades mais abertas o professor desempenha um papel fundamental de suporte aos estudantes (Kirschner, Sweller, \& Clark, 2006).

Dentre os principais impedimentos que os professores experimentam para implementar o EnCI estão a pouca motivação e habilidade dos estudantes, a falta de habilidades pedagógicas, o conhecimento inadequado de $\mathrm{NdC}$, a falta de suporte administrativo e de materiais curriculares adequados (Roehrig, \& Luft, 2004); além das dificuldades em guiar os estudantes no processo de investigação, como auxiliálos a formular questões científicas e planejar a investigação (van Uum et al., 2016). Os professores sofrem resistência dos alunos que também agem de acordo com seus sistemas de crenças e conhecimentos (Owens, Sadler, Barlow, \& Smith-Walters, 2017) que envolve a imagem de estudantes passivos recebendo conhecimento transmitido pelos professores.

A implementação do EnCI é influenciada por vários fatores, mas acreditamos que os conhecimentos e as crenças que os professores desenvolvem sobre ensino e 
aprendizagem ocupam um papel de destaque. Compreender os desafios e dilemas que os professores enfrentam ao pensar e atuar na perspectiva do EnCI, levando em consideração suas crenças e concepções, é importante para compreendermos o que inibe os professores na adoção dessa abordagem e refletirmos sobre os processos de formação docente.

\begin{tabular}{|c|c|}
\hline Fases e Subfases & Definições \\
\hline Orientação & $\begin{array}{l}\text { Processo de estimular a curiosidade sobre um tema e definir o desafio de } \\
\text { aprendizagem estabelecendo uma pergunta ou problema. }\end{array}$ \\
\hline Conceitualização & Processo de estabelecer questões e/ou hipóteses baseadas em teorias. \\
\hline Questionamento & $\begin{array}{l}\text { Processo de gerar perguntas de pesquisa baseadas no problema } \\
\text { estabelecido. }\end{array}$ \\
\hline Geração de hipóteses & Processo de gerar hipóteses baseadas no problema. \\
\hline Investigação & $\begin{array}{l}\text { Processo de planejar a exploração ou experimentação, coletar e analisar } \\
\text { dados baseados no desenho experimental ou exploração. }\end{array}$ \\
\hline Exploração & $\begin{array}{l}\text { Processo de gerar dados de forma sistemática e planejadas com base na } \\
\text { pergunta de pesquisa. }\end{array}$ \\
\hline Experimentação & $\begin{array}{l}\text { Processo de desenhar e conduzir experimento a fim de testar uma } \\
\text { hipótese. }\end{array}$ \\
\hline Interpretação de dados & $\begin{array}{l}\text { Processo de produzir sentido a partir dos dados recolhidos e sintetizar } \\
\text { novos conhecimentos. }\end{array}$ \\
\hline Conclusão & $\begin{array}{l}\text { Processo de tirar conclusões a partir dos dados. Comparar inferências } \\
\text { feitas com base em dados com hipóteses ou questões de pesquisa. }\end{array}$ \\
\hline Discussão & $\begin{array}{l}\text { Processo de apresentar resultados de determinadas fases ou de todo o } \\
\text { ciclo de investigação, comunicando-se com os outros e/ou controlando } \\
\text { todo o processo de aprendizagem ou suas fases a partir da realização de } \\
\text { atividades reflexivas. }\end{array}$ \\
\hline Comunicação & $\begin{array}{l}\text { Processo de apresentar resultados de uma fase da investigação ou de } \\
\text { todo o ciclo de investigação para outros. }\end{array}$ \\
\hline Reflexão & $\begin{array}{l}\text { Processo de descrever, criticar, avaliar e debater todo o ciclo investigativo } \\
\text { ou uma fase específica. }\end{array}$ \\
\hline
\end{tabular}

Figura 1. Descrição das fases e subfases do ciclo investigativo para o Ensino de Ciências por Investigação

Fonte: traduzido e adaptado de Pedaste et al. (2015).

Considerando os muitos desafios enfrentados para se formar professores na perspectiva do EnCI, a formação inicial é um espaço privilegiado de engajamento nessa mudança, pois pressupõe estudantes motivados que ainda não consolidaram hábitos de ensino e, por isso, estariam supostamente mais aptos a incorporarem maneiras inovadoras de atuar na sala de aula. Entender como os professores em formação desenvolvem e compreendem as diferentes dimensões de seus conhecimentos e suas concepções é interessante para tentar iluminar um percurso formativo mais profundo.

Por isso, neste trabalho buscamos compreender quais são os conhecimentos e concepções que um grupo de licenciandos em Ciências Biológicas expressa sobre as 
possibilidades e desafios da prática do EnCI nos primeiros contatos com essa abordagem. $\mathrm{Na}$ visão dos licenciandos, quais as possibilidades que eles associam ao EnCI? Quais são os desafios apresentados pelos licenciandos antes mesmo de experimentarem o EnCI em sala de aula? Quais desses desafios e possibilidades são do âmbito do conhecimento pedagógico e quais são do âmbito o conhecimento do tema? Como o conhecimento sobre os estudantes e o contexto aparece nas reflexões de EnCI?

\section{Metodologia}

Analisou-se a produção escrita reflexiva individual de 46 licenciandos de Ciências Biológicas, realizada após uma sequência de atividades instrucionais de seis aulas semanais, de quatro horas cada, voltada para a aprendizagem sobre EnCI. As aulas estão descritas brevemente na Figura 2. As atividades contemplaram leituras sobre o tema, modelagem de estratégias de ensino de ciências por investigação, discussões em pequenos grupos e sistematização coletiva. As leituras deveriam ser feitas previamente à aula. Sobre essas, era solicitado um breve registro escrito a partir de perguntas orientadoras, com o objetivo de preparar os licenciandos para a discussão dos textos.

\begin{tabular}{|l|l|}
\hline Aula & Descrição \\
\hline 01 & $\begin{array}{l}\text { Apresentação da disciplina: programa, objetivos, tarefas, formas de avaliação. } \\
\text { Relato de grupos do ano anterior sobre suas experiências no estágio e na disciplina. } \\
\text { Apresentação da pesquisa vinculada à disciplina e entrega do Termo de Consentimento Livre } \\
\text { e Esclarecido. } \\
\text { Atividade 1 - Discussão inicial sobre o que é uma boa aula, a partir de matérias da mídia } \\
\text { aberta, para trabalhar concepções iniciais. }\end{array}$ \\
$\begin{array}{l}\text { Tema - O que observar e analisar em um estágio? } \\
\text { Discussão sobre os seguintes capítulos de Carvalho, A. M. P. (2012) Os estágios nos cursos de } \\
\text { licenciatura. São Paulo: Cengage Learning: } \\
\text { - Capítulo 3:Observações priorizando as Interações Verbais Professor-Aluno } \\
\text { - Capítulo 4:Observações Priorizando o Conteúdo Ensinado } \\
\text { - Capítulo 5:Observações Priorizando as Habilidade de Ensino do Professor } \\
\text { Atividade 2 - Elaboração de roteiros de observação para o estágio, em pequenos grupos. } \\
\text { Definição de enfoques para observação e instrumentos de coleta de dados. }\end{array}$ \\
\hline
\end{tabular}

Figura 2. Descrição das seis primeiras aulas da disciplina Estágio Supervisionado em Ensino de Biologia do Instituto de Biociências da Universidade de São Paulo (continua) 


\begin{tabular}{|c|c|}
\hline Aula & Descrição \\
\hline \multirow[t]{4}{*}{03} & Tema - EnCI: licenciandos como aprendizes e pensadores. \\
\hline & Discussão de casos de ensino: o que pensam os licenciandos sobre EnCI. \\
\hline & $\begin{array}{l}\text { Atividade } 3 \text { - Twirly - introdução a elementos da investigação científica (disponível em }<\text { http:// } \\
\text { msed.iit.edu/projectican/twirly.html }>\text { ). Descrição: os licenciandos recebem um material para } \\
\text { produzir um tipo de hélice de papel e devem gerar perguntas, realizar experimentações com o } \\
\text { material disponível e comunicar os resultados. Discussão posterior sobre as características da } \\
\text { atividade e suas possibilidades de aprendizagem. }\end{array}$ \\
\hline & $\begin{array}{l}\text { Apresentação, seguida de discussão, de exemplos de atividades investigativas no ensino } \\
\text { fundamental: vídeos produzidos pelo LAPEF/USP (disponível em: < http://paje.fe.usp.br/ } \\
\text { estrutura/index_lapef.htm>). }\end{array}$ \\
\hline \multirow[t]{4}{*}{04} & Tema - EnCI: licenciandos como aprendizes e pensadores. \\
\hline & $\begin{array}{l}\text { Discussão sobre o texto lido: Carvalho, A.M.P. (2013). O ensino de Ciências e a proposição } \\
\text { de sequências de ensino investigativas In A.M.P. Carvalho (Org.). Ensino de ciências por } \\
\text { investigação. São Paulo: Cengage Learning. }\end{array}$ \\
\hline & Discussão dos casos e atividades da aula anterior à luz da nova leitura. \\
\hline & $\begin{array}{l}\text { Atividade } 4 \text { - Tentilhões de Galápagos. (Disponível em: <http://bguile.northwestern.edu/>). } \\
\text { Descrição: A partir do conjunto de dados disponibilizados na plataforma os licenciandos } \\
\text { respondem uma pergunta, fundamentando sua resposta nas evidências disponíveis. }\end{array}$ \\
\hline \multirow[t]{6}{*}{05} & Tema - EnCI: licenciandos como pensadores. \\
\hline & $\begin{array}{l}\text { Discussão sobre o potencial pedagógico da atividade dos tentilhões de galápagos: papel do } \\
\text { professor, papel dos estudantes. }\end{array}$ \\
\hline & Discussão sobre o texto lido: (Scarpa, \& Silva, 2013). \\
\hline & $\begin{array}{l}\text { Sistematização dos princípios do EnCI: etapas do EnCI; características de uma boa explicação; } \\
\text { objetivos do ensino de ciências e alfabetização científica; especificidades da biologia. }\end{array}$ \\
\hline & Atividade 5 - Transformar protocolos de atividades práticas em atividades investigativas \\
\hline & $\begin{array}{l}\text { Discussão inicial nos grupos da elaboração da sequência didática investigativa a ser aplicada } \\
\text { no estágio supervisionado. }\end{array}$ \\
\hline \multirow[t]{5}{*}{06} & Tema - EnCI: licenciandos como pensadores e praticantes. \\
\hline & $\begin{array}{l}\text { Aprofundamento e sistematização dos elementos chave do EnCI, destacando as fases do ciclo } \\
\text { investigativo e o grau de abertura, a partir da discussão sobre os textos lidos: }\end{array}$ \\
\hline & $\begin{array}{l}\text { - Banchi, H., \& Bell, R. (2008). The many levels of inquiry: inquiry comes in various forms. } \\
\text { Science and Children, 46: 26-29. }\end{array}$ \\
\hline & $\begin{array}{l}\text { - Pedaste, M. et al. (2015) Phases of inquiry-based learning: definitions and the inquiry cycle. } \\
\text { Educational Research Review, 14: 47-61. }\end{array}$ \\
\hline & $\begin{array}{l}\text { Atividade } 6 \text { - Elaboração da sequência didática investigativa a ser aplicada na regência do } \\
\text { estágio supervisionado. }\end{array}$ \\
\hline
\end{tabular}

Figura 2. Descrição das seis primeiras aulas da disciplina Estágio Supervisionado em Ensino de Biologia do Instituto de Biociências da Universidade de São Paulo (continuação) 
Essa sequência de atividades foi a primeira etapa de uma disciplina de estágio supervisionado do curso de licenciatura. Nessa primeira fase da disciplina, os licenciandos realizavam a etapa de observação do contexto de estágio para posterior produção e aplicação de uma sequência didática investigativa. Os licenciandos aceitaram participar da pesquisa após terem sido informados sobre seus objetivos e procedimentos, momento em que assinaram o Termo de Consentimento Livre e Esclarecido. O projeto foi aprovado pelo Comitê de Ética do Instituto de Biociências da Universidade de São Paulo, sob o registro CAAE 65338316.8.0000.5464. Para garantir o sigilo de identidade, adotamos neste texto o uso de letras maiúsculas para identificar os licenciandos, quando necessário.

Para os escritos reflexivos, que teriam no máximo três páginas, chamados aqui de portfólios, solicitou-se uma reflexão sobre as vantagens e desvantagens do uso de EnCI, as possibilidades e desafios a serem enfrentados no uso do EnCI ao longo do estágio e a relação do tema com suas experiências prévias como pode ser verificado na Figura 3.

$1^{\circ}$ Portfólio - questões orientadoras

1.Levando em consideração os aspectos do ensino por investigação discutidos e construídos em aula, faça uma reflexão sobre as possíveis vantagens e desvantagens de sua utilização.

2. Como as suas experiências anteriores como aluno e professor se relacionam com as características do ensino de ciências por investigação discutidos em aula?

3.Espera-se que neste momento você e sua dupla já tenham vivenciado o contexto de estágio na escola escolhida. A partir de sua experiência nas aulas, leituras e a observação do contexto da escola de estágio, avalie a possibilidade de utilizar atividades investigativas e os principais desafios a serem enfrentados nesse contexto.

Note que a produção desse portfólio é extremamente particular e se dá de forma muito singular, logo você deve incluir seu ponto de vista e suas reflexões. Apesar de elementos e exemplos de suas experiências anteriores e de suas observações realizadas no estágio serem fundamentais para justificar suas ideias e reflexões, não basta apenas realizar uma descrição das suas observações ou atividades.

Figura 3. Orientações para produção dos escritos reflexivos pelos licenciandos

Foi realizada a análise de conteúdo (Bardin, 1997; Elo, \& Kyngäs, 2008) dos portfólios. A fase exploratória buscou identificar sentenças relacionadas por um lado às possibilidades e vantagens do EnCI e por outro aos seus desafios e desvantagens. Essas sentenças, à medida em que eram identificadas, eram também relacionadas a um dos domínios da base de conhecimento profissional docente, inspirada principalmente em Shulman (1987) mas com adaptações, especialmente no que diz respeito ao conhecimento do tema, para o qual foram discriminados elementos do EnCI, como as fases do ciclo investigativo, a partir de Pedaste et al. (2015), apresentadas na Figura 1, além de considerar a natureza da ciência e as práticas científicas, como proposto por Crawford e Capps (2016). A síntese do que consideramos para cada categoria é apresentada a seguir:

Conhecimento do tema: também chamado de conhecimento do conteúdo, 
inclui tanto a estrutura substantiva do conhecimento, que é a variedade de formas nas quais os conceitos e princípios de uma disciplina estão organizados para incorporar seus fatos, quanto a estrutura sintática da disciplina, que é o conjunto de formas pelas quais são estabelecidas as verdades e falsidades, validades e invalidades (Shulman, 1987). Consideramos nessa categoria, os conhecimentos de natureza da ciência e práticas científicas (Crawford, \& Capps, 2016), discriminando as fases e subfases do ciclo investigativo: orientação; conceitualização; questionamento, geração de hipótese; investigação, exploração, experimentação, interpretação de dados, conclusão, discussão, comunicação, reflexão (Pedaste et al., 2015).

Conhecimento pedagógico: princípios amplos e estratégias de manejo de sala e organização que transcendem o conhecimento do conteúdo (Shulman, 1987); manejo de sala, organização e preparação de materiais, como desenhar atividades, como elicitar os conhecimentos prévios, estratégias didáticas variadas como organizar atividades em grupo.

Conhecimento dos aprendizes: características sociais e de personalidade de indivíduos ou dos grupos de estudantes, genéricos ou específicos; suas dificuldades e seus conhecimentos prévios.

Conhecimento do contexto: contexto específico; no nosso caso, envolve a situação de estágio.

Além desses conhecimentos, consideramos na fase exploratória outras duas categorias que têm se destacado nos modelos relacionados à base de conhecimento profissional docente: o Conhecimento profissional específico de um tópico, que inclui os conhecimentos de estratégias e conteúdo para ensinar um tópico específico de ensino para um nível particular de desenvolvimento dos estudantes; e o Conhecimento Pedagógico de Conteúdo que se relaciona à ação docente na prática em um contexto de ensino particular (Gess-Newsome, 2015). Pela sua natureza, essas categorias não seriam aplicáveis ao tipo de dado esperado nos escritos analisados, que apresentavam uma abordagem mais genérica e uma reflexão teórica.

As sentenças identificadas foram então reduzidas a subcategorias descritivas. A relação das subcategorias com as categorias mais amplas dos domínios de conhecimento foi discutida com pesquisadores especialistas a fim de verificar a coerência dessa relação, conformando assim o sistema final de subcategorias. Esse sistema serviu de base para a segunda etapa da análise, na qual foi realizada nova leitura dos portfólios, contabilizando para cada um a presença de cada subcategoria. Todas as menções às possibilidades ou vantagens do EnCI foram agrupadas na macrocategoria "possibilidades", e todos os desafios e desvantagens foram agrupados em "desafios". O sistema final de categorias e subcategorias resultante da análise pode ser verificado nas Tabelas 1 e 2, na seção Resultados.

Enfatizamos que as subcategorias, apesar de terem sido construídas a posteriori, ou seja, a partir dos dados dos portfólios, estão alinhadas com a perspectiva teórica da base de conhecimento profissional docente, que configurou as categorias mais amplas 
usadas como filtros à priori. Elas também se alinham com a perspectiva do ensino por investigação, a partir da identificação temática das sentenças pelas macrocategorias Possibilidades e Desafios do EnCI e da composição da categoria de Conhecimento do Tema, que incluiu os elementos do ciclo investigativo, que não só faz parte do referencial teórico da pesquisa, mas também integra o repertório de referências dos próprios licenciandos. Essa categorização descritiva nos possibilita identificar as concepções dos licenciandos e avaliar quais possibilidades são reconhecidas, em quais dimensões do conhecimento se centram os desafios, e como os diferentes aspectos do conhecimento profissional se relacionam com o EnCI.

\section{Resultados}

A partir das análises foram construídas subcategorias que descrevem as possibilidades e os desafios do Ensino de Ciências por Investigação, mencionadas pelos 46 licenciandos em seus escritos reflexivos. Essas categorias e suas respectivas frequências, assim como sua classificação nas dimensões do conhecimento profissional, podem ser encontradas na Tabela 1, que descreve as possibilidades, e na Tabela 2 que descreve os desafios. Descreveremos os resultados primeiro em relação às possibilidades e em seguida em relação aos desafios, trazendo exemplos encontrados nos portfólios.

\section{Possibilidades: a compreensão do conceito de EnCI}

A característica mais mencionada pelos licenciandos quando se trata das possibilidades do EnCI é o protagonismo dos estudantes em relação ao seu próprio processo de aprendizagem. Essa categoria foi citada por $82,6 \%$ dos licenciandos e faz parte da dimensão de conhecimentos pedagógicos:

A principal vantagem é tornar o aluno um agente ativo no seu processo de aprendizagem, conscientizando-o de que ele também pode ser um agente construtor de conhecimento para a sociedade (subcategoria protagonismo do estudante, licenciando AV).

Em relação aos outros conhecimentos pedagógicos, grande parte dos licenciandos mencionou o EnCI como capaz de possibilitar a motivação dos estudantes $(39,1 \%)$ para as aulas, assim como a construção coletiva de conhecimento $(30,4 \%)$ :

As aulas ficam potencialmente muito mais interessantes do que no ensino tradicional de aulas expositivas e conteudistas.[...] fazer experimentação ou exploração (Pedaste et al, 2015) é algo que capta a atenção dos alunos, torna o ensino de ciências algo muito mais prazeroso do que o ensino tradicional (subcategoria motivação dos estudantes, licenciando I).

Permitir que eles [alunos] reflitam sobre o assunto com outras pessoas que pertencem a uma mesma zona de desenvolvimento proximal (em vez de simplesmente ouvir como espectadores as reflexões de um professor, que pertence a uma diferente ZDP), incentiva a interação social na construção do conhecimento (subcategoria construção coletiva de conhecimento, licenciando E). 
Tabela 1. Frequência das subcategorias relacionadas às possibilidades do Ensino de Ciências por Investigação encontradas na análise dos portfólios de licenciandos de Ciências Biológicas, agrupadas nas dimensões do Conhecimento Profissional Docente. $\mathrm{N}=46$.

\begin{tabular}{lc}
\hline Dimensões do Conhecimento Profissional e subcategorias relacionadas às características & $\%(\mathrm{n}=46)$ \\
instrucionais possibilitadas pelo EnCI & \\
\hline Conhecimento Pedagógico & 82,6 \\
Protagonismo dos estudantes & 39,1 \\
Motivação dos estudantes & 30,4 \\
Construção coletiva do conhecimento & 19,6 \\
Consideração dos conhecimentos prévios dos estudantes & 15,2 \\
Regulação da aprendizagem & 13,0 \\
Uso de diferentes estratégias pelo professor & \\
Conhecimento do Tema & 56,5 \\
Desenvolvimento de raciocínio lógico & 50,0 \\
Aprendizagem de práticas científicas & 45,7 \\
Reflexão e argumentação & 41,3 \\
Proposição de perguntas & 34,8 \\
Geração de hipóteses & 32,6 \\
Aprendizagem a partir da solução de um problema & 32,6 \\
Aprendizagem de conteúdos conceituais & 30,4 \\
Experimentação & 30,4 \\
Interpretação de dados & 30,4 \\
Desenvolvimento dos conteúdos procedimentais e atitudinais & 28,3 \\
Investigação (planejar e gerar dados de forma genérica) & 28,3 \\
Fazer conclusões a partir de dados & 26,1 \\
Participação na sociedade & 21,7 \\
Comunicação & 15,2 \\
Exploração & 8,7 \\
Aprendizagem sobre a natureza da ciência & 4,3 \\
Interação do estudante com o objeto & \\
\hline
\end{tabular}

Nove dos 46 licenciandos (19,6\%) relacionaram a consideração dos conhecimentos prévios dos estudantes ao EnCI, enquanto sete $(15,2 \%)$ indicaram a possibilidade de regulação da aprendizagem e seis $(13,0 \%)$ valorizaram a possibilidade do uso de diferentes estratégias na aplicação dessa abordagem, relacionado também ao nível de abertura. São exemplos das duas últimas categorias, respectivamente:

Quando o aprendizado ocorre através da investigação, um ponto importante a ser observado e destacado é o valor do erro e sua frequência nesse tipo de ensino. Uma vez que a premissa das atividades é colocar o aluno como protagonista na elaboração do conhecimento, é natural que apareçam erros em diversas etapas do processo. Como professores, devemos ter em mente que ao cometer incorreções, o aluno é convidado a 
rever e readequar os conhecimentos que já possui, construindo os novos. Sendo assim, é importante deixá-lo errar, desde que uma reflexão ocorra para que haja uma tentativa de acerto posterior (subcategoria regulação da aprendizagem, licenciando $\mathrm{N}$ ).

Outra vantagem que se destaca é a versatilidade com que ela [abordagem] pode ser realizada, podendo os alunos, por exemplo: elaborarem suas próprias perguntas ou serem direcionados à resolução de um problema proposto (subcategoria uso de diferentes estratégias, licenciando F).

Em relação ao que classificamos como conhecimento do tema, mais da metade dos licenciandos (56,5\%) associou o EnCI ao desenvolvimento de raciocínio lógico, o que incluiu raciocínio científico ou pensamento crítico, enquanto metade fez referência ao EnCI possibilitar a aprendizagem de práticas científicas:

Que eles possam ter contato com o pensamento científico desde o ensino básico, algo que nunca tive em minha formação e acredito que seja muito relevante na formação escolar, já que imprime uma forma de pensar totalmente diferente do senso comum e faz o estudante se familiarizar com a cultura científica (subcategoria desenvolvimento do raciocínio lógico e aprendizagem de práticas científicas, Licenciando I).

Em relação às habilidades científicas relacionadas às fases do ciclo investigativo (Pedaste et al., 2015), a categoria reflexão e argumentação foi a mais mencionada $(45,7 \%)$, seguida em ordem de frequência por proposição de perguntas $(41,3 \%)$; geração de hipóteses (34,8\%); experimentação e interpretação de dados (30,4\% cada); investigação (planejar e gerar dados de forma genérica) e fazer conclusões a partir de dados $(28,3 \%$ cada); comunicação $(21,7 \%)$ e exploração $(15,2 \%)$. Todas as fases foram citadas, sendo relativamente bastante mencionadas. Segue um exemplo:

[com o] ensino por investigação, mais alunos estariam aumentando a suas capacidades reflexivas e o poder de crítica e construção de um conhecimento argumentativo (subcategoria reflexão e argumentação, licenciando H).

Aprendizagem a partir da solução de um problema e aprendizagem de conteúdos conceituais foram mencionadas por 32,6\% dos licenciandos e o desenvolvimento dos conteúdos procedimentais e atitudinais por 30,4\%. Em 26,1\% dos portfólios, o EnCI apareceu como uma abordagem que favorece a participação na sociedade. Um trecho que indica essas três últimas categorias é:

Além disso, o ensino por investigação não prioriza apenas um tipo de conteúdo. Pelo contrário, conteúdos procedimentais a atitudinais são tão valorizados quanto os conceituais. A aprendizagem destes conteúdos auxilia o aluno a participar da sociedade na qual ele está inserido (subcategorias aprendizagem de conteúdos conceituais; desenvolvimento de conteúdos procedimentais e atitudinais; participação na sociedade, licencianda J).

Por fim, quatro $(8,7 \%)$ licenciandos mencionaram a possibilidade do EnCI para a aprendizagem sobre a natureza da ciência e dois $(4,3 \%)$ mencionaram que o EnCI permite a interação do estudante com o objeto. 
O conhecimento dos alunos e o conhecimento do contexto também aparecem nas reflexões relacionadas ao EnCI, mas em uma lógica diferente, pois as características relacionadas a essas dimensões são mencionadas como facilitadoras do uso do EnCI o que é diferente de serem características "possibilitadas pelo EnCI" tal como usamos para a nossa categoria mais ampla. Por isso essas dimensões não aparecem na Tabela 1. Nessa perspectiva, temos que $15,2 \%$ dos licenciandos mencionaram características relacionadas ao conhecimento dos alunos, colocando de maneira geral que alunos participativos e interessados, acostumados a trabalhar em duplas ou grupos facilitam o EnCI.

Em relação ao conhecimento de contexto, apareceu nos portfólios que a boa receptividade a esse tipo de instrução dos professores supervisores e demais membros das escolas-campo de estágio $(17,4 \%)$ facilita o EnCI, assim como uma menor quantidade de estudantes por sala $(4,3 \%)$ e a presença de determinados recursos na escola-campo como sala temática com modelos didáticos, equipamentos televisivos, jardim, biblioteca, entre outros (6,5\%). Dentro desse último grupo, um licenciando citou o acesso dos professores a computadores como uma característica que facilitaria o acesso a atividades investigativas disponíveis na rede virtual. Outros 6,5\% fizeram menção ao perfil instrucional da escola como vantagens para aplicação do EnCI, citando escolas que seguem um modelo construtivista, uma professora que já usa o EnCI e outra que está trabalhando com o tema "método científico".

\section{Desafios do EnCI na voz dos licenciandos}

Quando olhamos para o que os licenciandos reconhecem como desafios (Tabela 2), há um predomínio de itens associados ao conhecimento pedagógico, sendo que a questão do tempo aparece liderando a lista. 43,5\% dos licenciandos mencionaram que o EnCI exige maior demanda de tempo de aula para um tema ou para contemplar todo o conteúdo programático e $32,6 \%$ que exige maior quantidade de tempo e trabalho no planejamento da instrução.

Os licenciandos mencionam o pouco tempo que o professor tem disponível em aulas, a pressão de pais e gestores pelo ensino de certa quantidade de conteúdos conceituais, o fato das aulas terem uma curta duração e serem fragmentadas, além do tempo de aprendizagem de cada aluno ser diverso. Em relação ao tempo de planejamento, alguns associam essa dificuldade às condições de trabalho, já que o professor tem que dar aulas em mais turmas para conseguir um salário mais adequado. Um licenciando também citou o fato de no planejamento ser necessário "preparar diferentes cenários para a aula", usando como exemplos casos de atividades investigativas de maior grau de abertura, como um dos pontos relacionados às restrições de tempo. 
Tabela 2. Frequência das subcategorias relacionadas aos desafios do Ensino de Ciências por Investigação encontradas na análise dos portfólios de licenciandos de Ciências Biológicas, agrupadas nas dimensões do Conhecimento Profissional. $\mathrm{N}=46$

\begin{tabular}{|c|c|}
\hline $\begin{array}{l}\text { Dimensões do Conhecimento Profissional e subcategorias relacionadas aos desafios do } \\
\text { EnCI }\end{array}$ & $\%(n=46)$ \\
\hline \multicolumn{2}{|l|}{ Conhecimento Pedagógico } \\
\hline Maior demanda de tempo de aula para um tema ou para contemplar todo o conteúdo & 43,5 \\
\hline Maior demanda de tempo e trabalho no planejamento da instrução & 32,6 \\
\hline Produzir uma sequência didática investigativa adequada & 21,7 \\
\hline Promover ou manter a motivação dos estudantes & 19,6 \\
\hline Contemplar os diferentes níveis de dificuldade e interesse em um grupo & 19,6 \\
\hline $\begin{array}{l}\text { Orientação adequada dos estudantes ao longo da sequência e para o desenvolvimento de } \\
\text { reflexão e outras habilidades }\end{array}$ & 17,4 \\
\hline \multicolumn{2}{|l|}{ Conhecimento do Tema } \\
\hline Dificuldade em ensinar tema específico devido à sua natureza & 13,0 \\
\hline \multicolumn{2}{|l|}{ Conhecimento dos Aprendizes } \\
\hline Descomprometimento dos estudantes com a própria aprendizagem & 28,3 \\
\hline Pouco conhecimento/habilidade dos estudantes & 21,7 \\
\hline Estudantes com baixa frequência às aulas & 6,5 \\
\hline \multicolumn{2}{|l|}{ Conhecimento do Contexto } \\
\hline Indisponibilidade de recursos materiais e estruturais & 30,4 \\
\hline Hábito do ensino tradicional & 17,4 \\
\hline Condições inadequadas de trabalho & 15,2 \\
\hline \multicolumn{2}{|c|}{$\begin{array}{l}\text { É interessante observar nos escritos em relação ao tempo que, quando há } \\
\text { comparação com o ensino tradicional, o objeto de comparação não se limita à estratégia } \\
\text { expositiva de conhecimentos factuais, mas parece haver uma concepção compartilhada } \\
\text { de que esse ensino dito "tradicional" incorpora uma despreocupação com a aprendizagem } \\
\text { do aluno, não precisando de tempo de planejamento nem de avaliação, como no exemplo } \\
\text { a seguir: }\end{array}$} \\
\hline
\end{tabular}

A aplicação de uma série de sequências didáticas, para várias turmas diferentes pode ser incompatível com o tempo e disponibilidade do professor, afinal, não basta a aplicação da sequência, a atividade deve ser bem planejada assim como a avaliação deve ser feita com qualidade (subcategoria maior quantidade de tempo e trabalho no planejamento da instrução, licenciando Q).

Conseguir produzir uma sequência didática investigativa adequada foi considerado um desafio por $21,7 \%$ dos licenciandos. Para além da menção de que planejar uma sequência de atividades era desafiador, foram citadas dificuldades em: conectar conteúdos, objetivos e a forma de intervenção; criar um ambiente favorável; elaborar boas situações-problema; planejar "passo-a-passo" uma sequência bem definida para atingir os objetivos e pensar uma atividade onde o aluno seja protagonista.

Promover ou manter a motivação e interesse dos estudantes foi considerado 
um desafio por 19,6\%. Por exemplo:

Outro problema sério, embora menos grave, seria conseguir prender a atenção dos alunos no momento de contextualizar o assunto que será abordado, empolgá-los com a ideia de fazer uma sequência de aulas investigativas, fazer com que todos compreendam qual é o problema central, e também fazer com que eles mantenham uma postura apropriada nessas aulas, especialmente ao longo de trabalhos em grupo (subcategoria promover ou manter a motivação e interesse dos estudantes, licenciando E).

A mesma frequência $(19,6 \%)$ foi encontrada para o desafio de contemplar os diferentes níveis de dificuldade e interesse em um grupo. Nessa categoria, em relação à diversidade dos alunos foram contemplados os diferentes ritmos de aprendizagem e dificuldades, diferentes perfis de alunos e perfis das turmas, além de alunos com deficiências (físicas ou intelectuais) como no exemplo a seguir:

Considerando esses pontos, os principais desafios são de criar uma atividade investigativa que permita a participação de todos os alunos, não sendo muito básica para aqueles que estão mais avançados, nem muito difícil para aqueles que possuem muita dificuldade (subcategoria contemplar os diferentes níveis de dificuldade e interesse em um grupo, licenciando $\mathrm{AV})$.

Em relação à orientação adequada dos estudantes ao longo da sequência para o desenvolvimento de reflexão e outras habilidades $(17,4 \%)$, os licenciandos se referiram aos desafios de "orientar os alunos sem entregar a resposta"; "guiar as discussões"; "orientação dos alunos no decorrer da atividade"; "promover o debate mais reflexivo junto com os alunos e incentivá-los a formular perguntas" e "abertura para escuta/observação e modificações frequentes no planejamento ao longo do percurso". Essa categoria aponta para as ações práticas do cotidiano profissional, exemplificada com o trecho a seguir:

E isso só enfatiza ainda mais a necessidade de treinar e entender o que é uma tutoria, o que é uma mediação, o que é encaminhar e quais perguntas devemos fazer para que os alunos se enveredem na investigação (subcategoria orientação adequada dos estudantes ao longo da sequência para o desenvolvimento de reflexão e outras habilidades, licencianda $\mathrm{M})$.

Os desafios citados até aqui foram classificados como conhecimentos pedagógicos. Os desafios relacionados ao conhecimento do tema apareceram com uma única subcategoria: dificuldade em ensinar tema específico devido à sua natureza $(13,0 \%)$. Nessa subcategoria, foi citada a complexidade dos sistemas biológicos junto às restrições éticas e temporais da sala de aula, além da necessidade de amostragem e papel do acaso, como limitações para abordar temas específicos, o que tornaria difícil utilizar o EnCI. Foram mencionados, ainda, "que nem todo assunto a ser abordado é passível de experimentação" e "o desafio de discutir, ao final dos experimentos/explorações que todas as interpretações são versões e que nenhuma é mais verdadeira do que a outra."

Os licenciandos também expressaram conhecimentos dos aprendizes que 
foram associados a desafios para o EnCI, referindo-se ao estágio. Esses foram: descomprometimento dos estudantes com a própria aprendizagem $(28,3 \%)$, pouco conhecimento/habilidade dos estudantes $(21,7 \%)$, estudantes com baixa frequência às aulas $(6,5 \%)$ e outras duas citações não categorizadas individualmente, mas compondo a categoria outros.

Em relação ao descomprometimento dos estudantes, os licenciandos citaram, partindo da própria observação de estágio, comportamento de indisciplina, desinteresse, passividade, acomodação, desrespeito ao professor e aos colegas, como no exemplo:

A desvantagem aqui [do EnCI] é a de ter necessidade dos alunos estarem dispostos a atividade. [...] o nível de dificuldade será elevado. Pois os alunos, mesmo os de $9^{\circ}$ ano, são pouco participativos e estão acostumados com a passividade, ou seja, apenas copiar textos da lousa ou questões (subcategoria descomprometimento dos estudantes com a própria aprendizagem, licenciando $\mathrm{H})$.

Em um dos casos nessa categoria, o perfil de comportamento não foi a desmotivação, mas quase seu oposto. Umalicencianda, que presenciou aulas investigativas com maior grau de abertura nos primeiros anos do ensino fundamental II, mencionou que os estudantes, por serem novos, teriam a "impressão de que a aula é uma grande brincadeira e não é levada à sério como outras disciplinas do currículo" (licencianda AR). No entanto, o descompromisso é prevalente, sendo que um dos licenciandos avaliou a questão comportamental como impeditiva para o ensino de ciências mencionando que

Os alunos não conseguem conviver com diferenças e qualquer visão diferente é recebida com agressividade e xingamentos.[...] acredito que o EI [EnCI] não seria recomendado pois exige muito mais do professor que neste momento das ERP [escolas da rede pública] precisa se preocupar com outros problemas [comportamentais] (licenciando AI).

Em relação ao pouco conhecimento ou habilidade dos estudantes, os licenciandos citaram que "os alunos não estão habituados a refletirem, construírem uma opinião crítica ou a analisar dados de experimentação e até mesmo de relacionar o experimento com o tema"; tem "dificuldade de leitura"; "não sabem o que fazer com autonomia", "não estão familiarizados com o fazer ciência"; "possuem grandes dificuldades para interpretar dados e fazer conclusões", além de dificuldade de escrita.

O caso dos estudantes com baixa frequência às aulas foi observado especialmente no contexto de estágio com Educação de Jovens e Adultos e foi mencionado como um desafio por produzir um prejuízo no acompanhamento da sequência didática, criando descompassos entre os estudantes.

Conhecimentos do contexto também estiveram presentes, mais uma vez referindo-se ao estágio e eventualmente outras experiências particulares. A indisponibilidade de recursos materiais e estruturais foi a categoria mais marcante desse conjunto, com 30,4\% de presença nos portfólios. Nessa categoria, os licenciandos se referiram à indisponibilidade de materiais, laboratório, sala de ciências e outros menos específicos, como recursos digitais, sala de informática, além da própria estrutura de trabalho para o professor. 
Desconstruir o hábito do ensino tradicional em favor de uma perspectiva construtivista (de professores ou alunos) apareceu em 17,4\% dos portfólios. Os licenciandos consideraram o desafio em relação tanto aos costumes dos alunos quanto dos professores e mencionaram:

O desafio consiste em vencer o paradigma da própria formação e aprender a técnica de ensino investigativa sem ter passado pela experiência de aluno desta técnica; ou seja, sem saber a visão do aluno perante essa (subcategoria hábito do ensino tradicional, licencianda $\mathrm{AB})$.

Ressalva-se, em relação a hábito e concepção de ensino, que apesar de muitos portfólios mencionarem a necessidade de mudar a visão de ensino transmissivoconteudista para uma abordagem mais construtivista, concepções resistentes também apareceram, como neste exemplo em que a licencianda considera impossível outra estratégia que não a aula expositiva devido à grande quantidade de conteúdo a ser decorado, sem questionar, no entanto, o modelo "decoreba":

Confesso que mesmo na graduação algumas matérias não saíram do molde "decoreba", até por ser quase impossível uma outra estratégia didática. Por exemplo, com a disciplina Vertebrados, eu não consigo imaginar uma outra maneira a ser dada, mesmo com os conhecimentos que estou adquirindo desta disciplina, por ser uma matéria de extenso conteúdo. E aqui eu coloco minha principal angústia em relação ao ensino em investigação: o tempo (exemplo de uma concepção resistente ao EnCI expressa pela licencianda $\mathrm{X}$, ao mesmo tempo em que ela expressa a subcategoria maior demanda de tempo de aula para um tema ou para contemplar todo o conteúdo).

Condições inadequadas de trabalho $(15,2 \%)$ também foram citadas. Nesse caso, os desafios referem-se aos baixos salários da profissão, às salas muito cheias, à falta de apoio escolar, motivação e reconhecimento.

\section{Discussão}

Nos portfólios analisados, os licenciandos tiveram a oportunidade de expressar seus conhecimentos e concepções sobre o EnCI no contexto da disciplina. Como subsídios à produção de suas reflexões, a disciplina promoveu (i) leituras e discussões que apresentaram as características do EnCI; (ii) duas atividades modelos (Twirly e Tentilhões de Galápagos) que possibilitaram que os licenciandos vivenciassem essa abordagem na posição de estudantes e refletissem sobre suas características pedagógicas; e (iii) uma tarefa de transformação de uma atividade didática não-investigativa em investigativa.

Em relação ao conteúdo que o EnCI possibilita, nota-se que os licenciandos reconhecem, para além do conteúdo conceitual, as práticas científicas como objeto de ensino, tanto de maneira genérica (50\%) quanto identificando mais especificamente as práticas relacionadas às diferentes fases do ciclo investigativo, tais como proposição de perguntas, geração de hipóteses, experimentação, interpretação de dados, fazer conclusão a partir de dados. 
O desenvolvimento de raciocínio lógico, indicado em mais da metade dos portfólios (56,5\%), inclui o pensamento crítico ou científico e se refere a um processo cognitivo essencial na ciência pelo qual é possível tecer conclusões baseadas em evidências, ou ainda avaliar um conhecimento a partir do seu embasamento. A prática reflexão e argumentação, igualmente bastante citada (46\%), também se relaciona à avaliação do processo de construção de conhecimento ou suas etapas, mas, além disso, expressa uma maneira de regulagem do processo de aprendizagem, incluindo tanto a autorreflexão como a reflexão coletiva.

A presença dessas categorias contemplam a dimensão dos objetivos epistêmicos para o ensino de ciências, relacionados a como o conhecimento é produzido e avaliado (Duschl, 2008) e parecem apontar para a superação do desafio de valorizar as práticas científicas e a dimensão do julgamento epistêmico exposto por Kelly (2014) para o EnCI, além de superar a concepção docente que associa o EnCI com atividades práticas ou experimentais ao permitir que as ações manipulativas se transformem em ações intelectuais por meio da reflexão e argumentação (Carvalho, 2013; Munford \& Lima, 2007; National Research Council, 2000).

Além disso, o fato de uma parte dos licenciandos ter indicado a possibilidade do uso de diferentes estratégias mostra a perspectiva de que o EnCI não é uma abordagem fechada, com um método único específico ou uma cartilha a ser seguida, mas que abarca uma diversidade de formas de ser praticado. Podemos supor também que essa visão sobre a possibilidade de uso de diversas estratégias pode revelar um entendimento da própria diversidade da ciência em seus métodos e percursos, como evidenciado na seguinte citação:

Outros aspectos que considero interessantes são a flexibilidade e a abrangência do ensino por investigação. Mas essa noção só se tornou mais clara ao longo das aulas de ESEB. Com relação à primeira vantagem, vejo que está relacionada à própria dinâmica do ensino por investigação. Por exemplo, há vários níveis de investigação que o professor pode propor para seus alunos (investigação aberta, estruturada, fechada); ou flexibilidade na ordem em que será feita as etapas de investigação (licencianda AU).

Entretanto, ainda no âmbito de conteúdos e objetivos de ensino, foi pouco expressiva nos portfólios a menção à Natureza da Ciência $(\mathrm{NdC})(8,7 \%)$. Dois pontos nos ajudam a interpretar esse dado no contexto desta pesquisa: (i) o critério de categorização; e (ii) os subsídios da disciplina. Sobre os critérios, para esta categoria consideraram-se as sentenças que continham o termo natureza da ciência ou se referiam à compreensão do funcionamento da ciência ou de seu papel na sociedade, sem capturar elementos de $\mathrm{NdC}$ expressos sob outras formas, ou seja, as categorias não foram suficientemente refinadas para capturar aspectos mais específicos de NdC.

Um exemplo é a citação do licenciando Q, segundo a qual a partir das práticas científicas, o indivíduo seria "capaz de compreender que a produção científica pode ter interpretações distintas, sem que isso signifique que a ciência é falha como método de construção do conhecimento, mas sim que é autorregulável e depende dessas 
interpretações". Ainda que expresse uma compreensão de ciência, a citação não foi classificada na categoria em questão por não se referir à $\mathrm{NdC}$ de uma maneira específica. Em relação aos subsídios da disciplina, nenhum dos textos aborda de maneira minuciosa a discussão sobre $\mathrm{NdC}$, nem suas relações com o ensino de ciências ou com o EnCI. Essas duas condições explicariam a baixa expressão dessa categoria.

Considerando o âmbito do conhecimento pedagógico, os licenciandos demonstraram concepções que incluem elementos importantes dos pressupostos socioconstrutivistas para o EnCI (Carvalho, 2013; Windschitl, 2002). O fato de 82,6\% reconhecerem que o EnCI possibilita o protagonismo dos estudantes, somado às menções sobre promover a motivação e construção coletiva do conhecimento e, de forma mais modesta, a consideração dos conhecimentos prévios dos estudantes e a regulação da aprendizagem, configura a presença de uma concepção de aprendizagem centrada no aprendiz em contraposição à visão centrada no professor (Lotter, Rushton, \& Singer, 2013; Voet \& De Wever, 2016). Esse dado indica que os licenciandos visualizam o EnCI como uma forma de concretizar os princípios socioconstrutivistas, superando uma dificuldade recorrente para os professores de forma geral que é compreender e visualizar um modelo de ensino que tenha uma orientação centrada no estudante (Windschitl, 2002).

No entanto, ainda que os licenciandos apresentem no discurso uma compreensão do EnCI que contempla conhecimentos pedagógicos e do tema coerentes com os subsídios apresentados na disciplina, quando se trata da dimensão prática as dificuldades de sobressaem. Dentre elas produzir uma sequência didática investigativa adequada; contemplar os diferentes níveis de dificuldade e interesse em um grupo e orientação adequada dos estudantes ao longo da sequência e para o desenvolvimento de reflexão e outras habilidades foram apontados em boa parte dos portfólios como desafios para a prática do EnCI. É interessante valorizar que os licenciandos reconhecem a diversidade dos aprendizes e a importância de atendê-la em relação a oportunizar aprendizagens para todos. Nota-se que essas dificuldades se referem, de maneira geral, a diferentes aspectos da interação entre professor e estudante, como se observa nas duas citações a seguir:

[...] é muito mais fácil dar uma aula na lousa do que problematizar os assuntos de maneira apropriada, planejar uma série de atividades para os alunos desenvolverem, orientar os alunos sem entregar a resposta, guiar as discussões reconhecendo o valor dos erros (subcategoria orientação adequada dos estudantes..., licenciando E).

Todas essas diferenças significam que teremos que adaptar a nossa sequência ao perfil de cada uma das cinco salas em que aplicaremos a sequência. Isso será difícil, principalmente considerando que geralmente o que mais pode fazer diferença no tratamento entre as salas são os detalhes: os tons de voz, o tipo de pergunta que fazemos, a maneira como conduziremos os alunos ao longo da sequência, entre outros (subcategoria contemplar os diferentes níveis de dificuldade.... licenciando $\mathrm{AH}$ ).

Essas dificuldades são esperadas, visto que os licenciandos não têm experiência 
docente e estão começando a pensar na sequência didática que irão aplicar no estágio. Observa-se que os desafios se relacionam a exercer uma prática pedagógica coerente com os princípios construtivistas. A perspectiva do EnCI representa uma mudança nos papéis de professor e estudantes em relação ao ensino transmissivo para uma forma mais interativa, complexa e imprevisível que exige mais esforço do professor (Windschitl, 2002). Entretanto, é preciso considerar também que a aprendizagem da profissão ocorre ao longo da construção de uma carreira e o contato com a prática em sala de aula é uma fonte importante do desenvolvimento dos saberes (Tardif, 2012). Nesse sentido, o estágio com regência é de grande relevância para oportunizar experiências em situações reais, em que o licenciando conte com o apoio de profissionais mais experientes, para que possa desenvolver seu conhecimento pedagógico de conteúdo (Gess-Newsome, 2015) e o saber da prática relacionados ao EnCI.

Relacionada a essa dimensão construtivista, está o desafio do EnCI mais citado pelos licenciandos: a maior demanda de tempo de aula para um tema ou para contemplar todo o conteúdo programático, indicada em quase metade dos portfólios. O desafio do tempo e do conteúdo é recorrente na literatura (Krämer et al., 2015) e para melhor compreendê-lo é necessário buscar quais seriam os referentes de comparação, tanto para o conteúdo como para o tempo, já que as citações não os mencionam.

De fato, aprender leva tempo. Particularmente, no ensino de ciências os estudantes precisam de tempo para explorar, fazer observações, errar e refazer, ler, pesquisar, formular perguntas, enfim, se engajar em atividades que poderão levar à construção de aprendizagens relevantes (Tobin \& McRobbie, 1996). Sobre a relação do tempo com o processo de investigação, Paula (2017) ressalta que

o ato de investigar implica investir tempo e energia na busca de uma resposta à pergunta que dá sentido à investigação. A extensão ou duração do processo de investigação, por sua vez, depende de fatores objetivos, tais como o tempo disponível para conduzir a investigação, tanto quanto de fatores subjetivos, como a sensação de satisfação ou insatisfação em relação à quantidade e à qualidade dos conhecimentos produzidos e das experiências vivenciadas ao longo do processo (Paula, 2017, p.95).

Assim, o tempo disponível é um condicionante tanto da extensão ou profundidade da aprendizagem, quanto da extensão do processo investigativo e, se ele não puder ser ajustado, pode se tornar um fator limitante. Porém, a recorrência dessa fala e a falta de um referente objetivo nos leva a associar esse desafio à ideia de mito cultural de Tobin e McRobin (1996). Os mitos seriam um conjunto de imagens, representações, definições ou justificativas ideais que são tomadas como medida de pensamento e prática e servem como referentes para ações intuitivas em um determinado contexto social. Os elementos que os originam podem estar presentes no cotidiano da sala de aula. O mito não é uma ideia certa ou errada, mas são crenças difusas no meio cultural que impregnam a experiência e o significado das ações dos indivíduos.

Em nenhuma citação dos licenciandos aparece menção a outra estratégia mais eficiente em termos de aprendizagem, ou seja, outra situação em que se aprenderia o 
mesmo conteúdo em menos tempo. O que nos parece é que esse conteúdo a ser ensinado toma como referência uma visão de ensino centrada na disciplina, em contraposição a uma visão centrada no aprendiz, pressupondo uma lista de temas e conceitos de Ciências ou Biologia, alinhada à perspectiva transmissiva-conteudista. Um dos poucos casos em que a necessidade de tempo aparece justificada nos portfólios aponta para essa interpretação:

Como [o EnCI] é uma estratégia que prevê a construção do conhecimento, um tempo maior é necessário para desenvolver em sala os temas que serão abordados. Ao tratarse, principalmente, de escola com currículos com extensos conteúdos conceituais, essa maior demanda de tempo pode ser uma desvantagem e impossibilitar sua real aplicação na escola (subcategoria maior demanda de tempo..., licencianda $\mathrm{AO}$ ).

Podemos relacionar essa ideia ao mito da eficiência docente de Tobin e McRobbie (1996), que considera que o tempo é insuficiente, o currículo inclui muitos conteúdos, o currículo é uma pressão externa fora do controle do professor e que cobrir o conteúdo é uma obrigação ou necessidade que se sobrepõe à aprendizagem. $\mathrm{O}$ mito cultural tende a ser um referente não só para o professor, mas também para os demais sujeitos da comunidade como alunos, pais e gestores.

Esse desafio relativo ao tempo parece se contrapor à visão centrada no aprendiz que aparece nos portfólios em relação às possibilidades do EnCI, revelando uma tensão que pode ser caracterizada como um dos dilemas para o ensino construtivista indicados por Windschitl (2002). O autor enquadra os dilemas dos professores para ensinar de forma construtivista em quatro categorias: conceitual, pedagógico, cultural e político. Os dilemas conceituais são referentes à compreensão dos princípios filosóficos, psicológicos e epistemológicos do construtivismo. Os pedagógicos são referentes a como desenhar experiências de aprendizagem, ensinar e avaliar de forma coerente com os princípios construtivistas. Os culturais estão relacionados à reorientação radical dos papéis da sala de aula e às expectativas necessárias para acomodar o etos construtivista. Os políticos se referem à resistência de partes interessadas na comunidade escolar quando as normas institucionais são questionadas e as rotinas de privilégio e autoridade são perturbadas. Esse quadro nos dá uma imagem da amplitude de questões enfrentadas por professores que se propõem a se aventurar no ensino construtivista.

A tensão explicitada em relação ao tempo de ensino pode ser entendida como parte de um dilema cultural, que se assenta sobre a necessidade de questionamento da cultura escolar pré-estabelecida e de seus valores, ou seja, do currículo pressuposto, da quantidade de conteúdo, do papel esperado do professor em cumprir esse currículo; parte de um dilema pedagógico, em conseguir ajustar a prática de ensino por investigação ao tempo disponível; e também parte de um dilema conceitual, pela necessidade de compreender as bases epistemológicas sobre as quais o ensino construtivista opera. $\mathrm{O}$ fato de grande porção da experiência de formação desses licenciandos ter sido de acordo com o paradigma transmissivo-conteudista favorece a permanência desses mitos que podem preveni-los de se arriscar a atuar segundo uma abordagem diferente de ensino. 
Ainda sobre esse mito, destacamos como esses licenciandos veem o currículo como algo determinado, sem possibilidade de escolhas ou decisões, ao qual o professor é submetido e deve cumprir, e não como algo em constante construção tendo o professor como um de seus principais atores. A instrução construtivista sendo centrada na perspectiva do aprendiz, que considera seus conhecimentos prévios e conteúdos relevantes para seu contexto, pressupõe certa autonomia do professor nas escolhas curriculares (Windschitl, 2002). Portanto, desenvolver uma visão de currículo emancipatória nos licenciandos, na qual haja um empoderamento da sua ação, nos parece uma medida relevante para ajudá-los a superar esse mito e lidar com as imposições do cotidiano profissional.

O segundo desafio mais citado refere-se à necessidade de maior tempo de planejamento da instrução. Nesse desafio, está envolvido o tempo de aprender uma nova perspectiva de ensino e aprendizagem, sob a qual os licenciandos e docentes não têm experiência, além da pouca experiência da própria comunidade escolar como um todo, o que faz com que haja ainda poucos materiais disponíveis em que o professor possa apoiar o seu planejamento didático, como sequências didáticas investigativas para diferentes temas. Nesse cenário, o tempo de planejamento do ensino pode incluir também o tempo de produzir material e pensar a organização do currículo escolar, sendo a falta de materiais e recursos disponíveis o terceiro desafio mais citado, que também tem sido apontado por licenciandos em outros contextos (Krämer et al., 2015).

A motivação dos estudantes é outra tensão que se manifesta nos escritos dos licenciandos, pois $39,1 \%$ reconhecem o EnCI como capaz de promover a motivação nos estudantes, enquanto $19,6 \%$ deles enxergam isso como um desafio. Da mesma forma, $82,6 \%$ veem o EnCI como promotor de estudantes protagonistas da sua aprendizagem, enquanto $23,9 \%$ indicam o descompromisso ou desinteresse como um desafio ao EnCI. Ainda, $21,7 \%$ identificam como dificuldade o pouco conhecimento ou habilidade dos estudantes, ou seja, para uma parcela dos licenciandos, o EnCI depende de estudantes motivados e habilidosos.

A falta de motivação e habilidade dos estudantes é recorrente no relato de professores como um dificultador de utilização do EnCI. Krämer e colaboradores (2015) analisaram 33 licenciandos que passaram por um curso sobre EnCI, produziram e aplicaram aulas baseadas nessa abordagem. Mais da metade deles, $54 \%$, relatou terem tido dificuldades em manter o interesse, atenção e motivação dos alunos e $52 \%$ indicaram a falta de experiência dos alunos como um limitante. Esses dois itens também foram prevalentes nos relatos de professores iniciantes na pesquisa de Roehrig e Luft (2004).

É fato que o interesse e a motivação apresentam impacto positivo na aprendizagem (Blankenburg, Höffler, \& Parchmann, 2016). Owens e colaboradores (2017) chamam atenção para um possível paradoxo na literatura em relação à motivação de estudantes para abordagens de "aprendizagem ativa" que reflete em parte a tensão encontrada em nossos dados: enquanto há um número expressivo de artigos que indicam que a aprendizagem ativa promove a motivação, há também relatos de professores que indicam resistência 
por parte dos estudantes a essa abordagem. Os autores investigaram a percepção de estudantes de ciências em nível superior sobre uma estratégia instrucional que atende aos pressupostos do EnCI. Parte desses estudantes avaliou que a estratégia aumentava o interesse no tema (26\%) e aumentava a motivação para estarem mais bem preparados para as aulas (16\%); ao mesmo tempo, 29\% declaram preferir uma forma de instrução mais autoritária e centrada no professor.

Os dados obtidos por Owens et al. (2017) ajudam a dar sentido à tensão observada na percepção dos nossos licenciandos. Características intrínsecas à aprendizagem ativa, como maior engajamento do estudante, desenvolvimento de habilidades de raciocínio, uso da criatividade e troca de ideias com os pares são consideradas motivadoras na maioria dos casos. Entretanto, sempre haverá algum tipo de resistência por parte dos alunos, seja uma resistência a um maior engajamento intelectual que demanda maior esforço, seja por operarem dentro do paradigma transmissivo-conteudista. Isto, por sua vez, demanda um esforço por parte do professor em justificar e explicar os objetivos e a lógica por trás de abordagens como o EnCI.

Em relação à falta de experiência e habilidade, é preciso ter em mente que os estudantes aprendem novos conceitos baseados em conceitos prévios. Portanto, não é razoável esperar que os alunos sejam capazes de induzir conceitos científicos sofisticados a partir de fenômenos empíricos (Kelly, 2014). Algumas reflexões dos licenciandos revelam a concepção de que no EnCI os alunos devem conseguir resolver determinadas tarefas por si próprios, como na citação a seguir:

acredito fortemente na possibilidade de realizarmos uma atividade investigativa no nível "confirmation inquiry" (Banchi, 2008), na qual oferecemos um problema, o procedimento para resolvê-lo e a sua solução, claro que não de forma expositiva. Considerei utilizar este nível pois os alunos não estão familiarizados com o "fazer ciência", portanto não acho que seriam capazes de resolver o problema sozinhos, necessitando de nossa ajuda em todas as etapas (licencianda AE).

Práticas como observação, experimentação, inferência e explicação sem dúvida são desafiadoras para os novatos que não têm as bases epistêmicas e conceituais suficientes, mas são fundamentais para a aprendizagem sobre o funcionamento da ciência (Kelly, 2014). Os licenciandos pareceram desconsiderar que no EnCI é esperado que os professores guiem e orientem seus estudantes, mesmo em níveis investigativos mais abertos, dando suporte à realização das tarefas, modelando práticas, fornecendo feedback de forma explícita e consistente para reduzir a frustração dos alunos com práticas pouco familiares e desafiadoras (Owens et al., 2017). Esse suporte genuíno, o scaffolding ou andaime de Vigotski (2009), é fundamental para que os estudantes consigam se desenvolver em cada demanda específica e deve considerar o engajamento em atividades e no discurso da ciência com indivíduos mais experientes (Kelly, 2014). Nesse sentido, Kirschner et al. (2006) argumentam que o ensino por orientação mínima não tem mostrado benefícios de aprendizagem e que é necessário dar aos aprendizes instruções bastante específicas de como manipular cognitivamente as informações de 
forma direcionada aos objetivos de ensino.

A cultura escolar observada nos estágios, manifestada nos hábitos de professores e estudantes, foi uma das causas apontadas para a falta de habilidade dos estudantes, como nos seguintes relatos dos Licenciandos $\mathrm{T}$ e $\mathrm{H}$, respectivamente: "Acompanhamos turmas de $7^{\circ}$ ano com um forte histórico copista e que não acredita ser útil aprender conteúdo de ciência (pouco transporte ou visão de ciência na realidade)"; "os alunos não estão habituados a refletirem, construírem uma opinião crítica ou a analisar dados de experimentação e até mesmo de relacionar o experimento com o tema”. Somandose a isso, o hábito de ensino tradicional foi citado em $17,4 \%$ dos portfólios como um desafio.

Assim, essas citações evidenciam mais um item no dilema de ensino construtivista, no qual a realidade escolar, em que predomina o paradigma da transmissão de conhecimentos, é vista como um impedimento às ações dos licenciandos relacionadas ao EnCI, ao mesmo tempo em que eles reconhecem a necessidade e a possibilidade de mudança para um paradigma centrado na aprendizagem do estudante.

Adotar uma perspectiva construtivista de ensino tem sido desafiador para os professores desde as primeiras propostas de reformas educacionais. Os maiores desafios para o EnCI não estão apenas associados à questão de desenvolver novas habilidades, mas sim de compreender e visualizar como se dá o ensino nessa perspectiva, além da necessidade de uma reorientação da cultura de sala de aula, tendo os professores de lidar com um conservadorismo educacional em diversos âmbitos que não favorece o apoio à aprendizagem do aluno (Windschitl, 2002). O enfrentamento a esse desafio está ligado não apenas a uma mudança na área disciplinar, mas deveria envolver a comunidade escolar como um todo, inclusive no âmbito das decisões e pedagogias curriculares, coordenando os diferentes níveis escolares ao longo do tempo e as áreas disciplinares de um mesmo nível a favor da aprendizagem do conhecimento conceitual, dos critérios epistêmicos e das práticas sociais nos domínios da ciência (Kelly, 2014).

Destacamos que as dificuldades mencionadas pelos licenciandos concentram-se principalmente em relação ao domínio do conhecimento pedagógico. A baixa presença de desafios relacionados ao conhecimento do tema se justifica pelo fato de os estudantes não estarem lidando com nenhum tema biológico específico, além do contexto de formação ser um curso que desenvolve, em outras disciplinas, uma carga intensa de conhecimento específico de Biologia, o que pode lhes fornecer condições de maior autoconfiança nesse elemento. No entanto, essa interpretação não pode ser estendida às concepções de $\mathrm{NdC}$, que não são trabalhadas tão intensamente no curso. Estudantes de Ciências Biológicas brasileiros apresentaram dificuldades em reconhecer e interpretar práticas científicas e o papel das teorias na organização do conhecimento (Azevedo, \& Scarpa, 2017). Esse dado aponta que conhecimentos de NdC precisam ser apresentados para a reflexão dos professores em formação. Um conhecimento de conteúdo forte, que inclui uma visão contemporânea de $\mathrm{NdC}$, aliado a uma perspectiva de aprendizagem centrada no aluno, aumenta a probabilidade de que o EnCI seja implementado (Roehrig, 
\& Luft, 2004).

De forma a superar esses desafios na formação de professores, um caminho possível seria aumentar o repertório dos licenciandos em relação aos possíveis cenários de ensino construtivista, com maior investimento pedagógico na apresentação de modelos, incluindo atividades e estratégias de como orientar os estudantes para o desenvolvimento de conhecimentos e habilidades. Além disso, possibilitar que eles planejem e apliquem sequências didáticas investigativas nos estágios formativos, e reflitam coletivamente sobre as vivências, orientariam o desenvolvimento do saber prático. A citação a seguir evidência o valor de oferecer experiências concretas de EnCI para que os licenciandos possam visualizar mais possibilidades de ensino nessa perspectiva:

não fazia sentido para mim deixar que os alunos realizassem todas as etapas da sequência [ciclo investigativo]. Afinal, como se poderia ter controle de todos os tipos de pergunta que os alunos fariam? Foi então que tive uma experiência de desequilibração na atividade que fizemos do Twirly. Neste caso, nós mesmos formulamos as perguntas e conduzimos os experimentos e, mesmo assim, elas tinham muitos aspectos em comum com os outros grupos. Com todas as discussões que fizemos, entendi que não existe algo como o grau de liberdade ideal. Ele varia de acordo com a proposta e os objetivos da aula em questão (licenciando J).

Além disso, é fundamental que, na formação de professores, sejam levadas em consideração as concepções dos licenciandos que possam configurar obstáculos ao EnCI, assim como os dilemas e mitos culturais em jogo na mudança para uma perspectiva construtivista. Desta maneira, é importante tornar as concepções e os mitos explícitos e submetê-los à análise e profunda reflexão pelos licenciandos, na busca de construir coletivamente concepções e estratégias mais poderosas para a superação desses desafios.

\section{Conclusões e Implicações}

Já nos primeiros contatos com o EnCI, o grupo de licenciandos em Ciências Biológicas teve a possibilidade de confrontar os aspectos teóricos e a realidade do contexto escolar de estágio, manifestando tensões entre as possibilidades e desafios do EnCI. Em suas reflexões, os licenciandos trouxeram as principais características do EnCI, reconhecendo-o como uma forma de promover a aprendizagem e o desenvolvimento de conceitos e habilidades da ciência, especialmente sobre as práticas científicas, alinhando o conteúdo a uma perspectiva de aprendizagem centrada no estudante, coerente com os princípios socioconstrutivistas. Nesse sentido, eles puderam desenvolver conhecimentos pedagógicos e do tema sobre essa abordagem.

Ao mesmo tempo, eles manifestaram desafios, especialmente relacionados à dimensão da prática pedagógica, que (i) são coerentes com a falta de experiência em ensino esperada para essa fase de formação, (ii) se relacionam a condições sociais da profissão, (iii) se orientam por mitos culturais relacionados à docência e (iv) integram o dilema do ensino construtivista. Especialmente relacionado a esse último, manifestaramse tensões e contradições entre uma orientação de ensino centrada no professor, de 
perspectiva transmissiva-conteudista, e uma orientação centrada no aprendiz, com foco na aprendizagem e desenvolvimento cognitivo.

Nas reflexões dos licenciandos, o EnCI não supera os desafios construtivistas, mas ao mesmo tempo, se apresenta como uma possibilidade de encarar esses desafios na prática. Ao apresentar possibilidades de envolver os estudantes na elaboração de hipóteses, na construção e análise de dados, na comunicação e avaliação de ideias componentes do EnCI -, o estudante é colocado no centro do processo de aprendizagem, concretizando os pressupostos construtivistas por meio das práticas científicas, em um processo de ensino cuidadosamente orientado. Nesse sentido, conhecimento pedagógico, conhecimento do tema e conhecimento do contexto se integram e se transformam na constituição da prática docente.

Os principais desafios e angústias dos licenciandos para o EnCI referem-se ao conhecimento pedagógico, tanto em relação ao dilema construtivista como à dimensão do saber prático. Da mesma forma, o conhecimento do contexto e dos aprendizes aparecem no sentido de configurar desafios relacionados à prática pedagógica. O desenvolvimento de conhecimento do tema, incluindo o conhecimento de conteúdo conceitual, práticas científicas e $\mathrm{NdC}$, não constituem dificuldades nas reflexões desse grupo.

Este trabalho contribui para a compreensão de aspectos da aprendizagem de professores em formação, na constituição de seus conhecimentos e crenças sobre o Ensino de Ciência por Investigação. Analisar o impacto da formação subsequente na modificação dessas concepções a partir do maior contato com a prática no estágio e a reflexão sobre ela, assim como sua repercussão na atuação profissional desses estudantes, são possibilidades interessantes para futuras investigações que contribuiriam com o conhecimento da área de formação professores de Ciências e Biologia direcionada ao Ensino de Ciências por Investigação.

\section{Agradecimentos}

Agradecemos ao Programa de Pós-graduação Interunidades em Ensino de Ciências por apoiar esta pesquisa, à CAPES pelo financiamento e aos licenciandos e licenciandas de ESEB que autorizaram a coleta de dados.

\section{Referências}

Abd-El-Khalick, F., Boujaoude, S., Duschl, R., Lederman, N. G., Mamlok-Naaman, R., Hofstein, A., ... Tuan, H. L. (2004). Inquiry in science education: International perspectives. Science Education, 88(3), 397-419. https://doi.org/10.1002/sce.10118

Azevedo, N. H., \& Scarpa, D. L. (2017). Um levantamento em larga escala das concepções de natureza da ciência de graduandos de biologia brasileiros e os possíveis elementos formativos associados. Ensaio Pesquisa em Educação em Ciências, 19(e2794). https:// doi.org/10.1590/1983-21172017190121 
Banchi, H., \& Bell, R. (2008). The many levels of inquiry. Science and Children, (October), 26-29. https://doi.org/10.1111/j.1600-065X.2008.00760.x.SHP-1

Bardin, L. (1997). Análise de conteúdo. Lisboa: Edições 70.

Berry, A., Friedrichsen, P., \& Loughran, J. (Eds.). (2015). Re-examining Pedagogical Content Knowledge in Science Education. London: Routledge. https://doi. org/10.4324/9781315735665

Blankenburg, J. S., Höffler, T. N., \& Parchmann, I. (2016). Fostering Today What is Needed Tomorrow: Investigating Students' Interest in Science. Science Education, 100(2), 364-391. https://doi.org/10.1002/sce.21204

Borda Carulla, S. (Ed). (2012). Tools for Enhancing Inquiry in Science Education. The Fibonacci Project. Montrouge: Companion Resources for Implementing Inquiry in Science Education.

Capps, D. K., Crawford, B. A., \& Constas, M. A. (2012). A Review of Empirical Literature on Inquiry Professional Development: Alignment with Best Practices and a Critique of the Findings. Journal of Science Teacher Education, 23(3), 291-318. https://doi. org/10.1007/s10972-012-9275-2

Capps, D. K., Shemwell, J. T., \& Young, A. M. (2016). Over reported and misunderstood? A study of teachers' reported enactment and knowledge of inquiry-based science teaching. International Journal of Science Education, 38(6), 934-959. https://doi.org/10. 1080/09500693.2016.1173261

Carvalho, A. M. P. (2013). O ensino de ciências por investigação e a proposição de sequências de ensino investigativas. In A. M. P. de Carvalho (Ed.), Ensino de Ciências por Investigação: condições para implementação em sala de aula (pp. 1-20). São Paulo: CENGAGE Learning.

Crawford, B. A., \& Capps, D. K. (2016). What Knowledge Do Teachers Need for Engaging Children in Science Practices? Cognition, Metacognition, and Culture in STEM Education, (January), 1-24.

Duschl, R. (2008). Science Education in Three-Part Harmony: Balancing Conceptual, Epistemic, and Social Learning Goals. Review of Research in Education, 32(February), 268-291. https://doi.org/10.3102/0091732X07309371

Elo, S., \& Kyngäs, H. (2008). The qualitative content analysis process. Journal of Advanced Nursing, 62(1), 107-115. https://doi.org/10.1111/j.1365-2648.2007.04569.x

Fernandez, C. (2015). Revisitando a Base de Conhecimentos e o Conhecimento Pedagógico do Conteúdo (PCK) de Professores de Ciências. Ensaio: Pesquisa em Educação em Ciências, 17(2), 500-528. https://doi.org/10.1590/1983-21172015170211 
Gess-Newsome, J. (2015). A model of teacher professional knowledge and skill including PCK: Results of the thinking from the PCK summit. In A. Berry, P. Friedrichsen, \& J. Loughran (Eds.), Re-examining pedagogical content knowledge in science education (pp. 28-42). London: Routledge.

Gess-Newsome, J., \& Lederman, N. G. (Eds.). (1999). Examining Pedagogical Content Knowledge: the construct and its implications for science education. Dordrecht: Springer. https://doi.org/10.1007/0-306-47217-1

Helms, J., \& Stokes, L. (2013). A Meeting of Minds Around Pedagogical Content Knowledge: designing an international PCK summit for professional, community, and field development (PCK Summit Report). Retrieved from http://www.inverness-research.org/ reports/2013-05_Rpt-PCK-Summit-Eval-final_03-2013.pdf

Kelly, G. J. (2014). Inquiry Teaching and Learning: philosophical considerations. In M. Matthews (Ed.), International Handbook of Research in History, Philosophy and Science Teaching. (pp. 1363-1380). Dordrecht, Heidelberg, New York, London: Springer.

Kirschner, P. A., Sweller, J., \& Clark, R. E. (2006). Why Minimal Guidance During Instruction Does Not Work: An Analysis of the Failure of Constructivist, Discovery, Problem-Based, Experiential, and Inquiry-Based Teaching. Educational Psychologist, 41(2), 75-86. https://doi.org/10.1207/s15326985ep4102_1

Krämer, P., Nessler, S. H., \& Schlüter, K. (2015). Teacher students' dilemmas when teaching science through inquiry. Research in Science \& Technological Education, 33(3), 325-343. https://doi.org/10.1080/02635143.2015.1047446

Krasilchik, M. (2004). Prática de ensino de Biologia. São Paulo: Edusp.

Lotter, C., Harwood, W. S., \& Bonner, J. J. (2007). The Influence of Core Teaching Conceptions on Teachers' Use of Inquiry Teaching Practices. Journal of Research in Science Teaching, 44(9), 1318-1347. https://doi.org/10.1002/tea

Lotter, C., Rushton, G. T., \& Singer, J. (2013). Teacher Enactment Patterns: How Can We Help Move All Teachers to Reform-Based Inquiry Practice Through Professional Development? Journal of Science Teacher Education, 248, 1263-1291. https://doi. org/10.1007/s10972-013-9361-0

Lotter, C., Smiley, W., Thompson, S., \& Dickenson, T. (2016). The impact of a professional development model on middle school science teachers' efficacy and implementation of inquiry. International Journal of Science Education, 38(18), 2712-2741. https://doi.org/1 0.1080/09500693.2016.1259535

Marshall, J. C., Horton, R., Igo, B. L., \& Switzer, D. M. (2009). K-12 Science and Mathematics Teachers' Beliefs About and Use of Inquiry in the Classroom. International Journal of Science and Mathematics Education, 7(3), 575-596. https://doi.org/10.1007/ s10763-007-9122-7 
MEC (1998). Parâmetros Curriculares Nacionais, Ciências Naturais: Ensino de quinta a oitava séries. Brasília: MEC/SEF. Retrieved from http://portal.mec.gov.br/seb/arquivos/ pdf/ciencias.pdf

Minner, D. D., Levy, A. J., \& Century, J. (2010). Inquiry-based science instruction-what is it and does it matter? Results from a research synthesis years 1984 to 2002. Journal of Research in Science Teaching, 47(4), 474-496. https://doi.org/10.1002/tea.20347

Munford, D., \& Lima, M. E. C. de C. e. (2007). Ensinar Ciências por Investigação: em quê estamos de acordo? Ensaio Pesquisa Em Educação Em Ciências, 9(1), 89-111. https:// doi.org/10.1590/1983-21172007090107

National Research Council. (2000). Inquiry and the National Science Education Standards: A Guide for Teaching and Learning. Washington, D.C.: The National Academies Press. https://doi.org/10.17226/9596

National Research Council. (2012). A Framework for K-12 Science Education: practices, crosscutting concepts, and core ideas. Social Sciences. Washington, D.C.: The National Academies Press. https://doi.org/10.17226/13165

Owens, D. C., Sadler, T. D., Barlow, A. T., \& Smith-Walters, C. (2017). Student Motivation from and Resistance to Active Learning Rooted in Essential Science Practices. Research in Science Education, 1-25. https://doi.org/10.1007/s11165-017-9688-1

Paula, H. F. (2017). Fundamentos Pedagógicos para o Uso de Simulações e Laboratórios Virtuais no Ensino de Ciências. Revista Brasileira de Pesquisa em Educação em Ciências, 17(1), 75. https://doi.org/10.28976/1984-2686rbpec201717175

Pedaste, M., Mäeots, M., Siiman, L. A., de Jong, T., van Riesen, S. A. N., Kamp, E. T., ... Tsourlidaki, E. (2015). Phases of inquiry-based learning: Definitions and the inquiry cycle. Educational Research Review, 14, 47-61. https://doi.org/10.1016/j.edurev.2015.02.003

Roehrig, G. H., \& Luft, J. A. (2004). Constraints experienced by beginning secondary science teachers in implementing scientific inquiry lessons. International Journal of Science Education, 26(1), 3-24. https://doi.org/10.1080/0950069022000070261

Sandoval, W. A. (2005). Understanding students' practical epistemologies and their influence on learning through inquiry. Science Education, 89(4), 634-656. https://doi. org/10.1002/sce.20065

Sasseron, L. H. (2015). Alfabetização Científica, Ensino Por Investigação E Argumentação: Relações Entre Ciências Da Natureza E Escola. Ensaio Pesquisa em Educação em Ciências, 17(spe), 49-67. https://doi.org/10.1590/1983-2117201517s04

Scarpa, D. L., Sasseron, L. H., \& Silva, M. B. (2017). O Ensino por Investigação e a Argumentação em Aulas de Ciências Naturais. Tópicos Educacionais, 23(1), 7-27. 
Scarpa, D. L., \& Silva, M. B. (2013). A Biologia e o Ensino de Ciências por Investigação: dificuldades e possibilidades. In A. M. P. Carvalho (Ed.), Ensino de Ciências por Investigação: condiçães para implementação em sala de aula. São Paulo: Cengage Learning.

Shulman, L. (1987). Knowledge and Teaching: Foundations of the New Reform. Harvard Educational Review, 57(1), 1-23. https://doi.org/10.17763/haer.57.1.j463w79r56455411 Tardif, M. (2012). Saberes docentes e formação profissional. Petrópolis: Vozes.

Tobin, K., \& McRobbie, C. J. (1996). Cultural myths as constraints to the enacted science curriculum. Science Education, 80(2), 223-241. https://doi.org/10.1002/(SICI)1098237X(199604)80:2<223::AID-SCE6>3.0.CO;2-I

van Uum, M. S. J., Verhoeff, R. P., \& Peeters, M. (2016). Inquiry-based science education: towards a pedagogical framework for primary school teachers. International Journal of Science Education, 38(3), 450-469. https://doi.org/10.1080/09500693.2016.1147660

Vigotski, L. S. (2009). A construção do Pensamento e da Linguagem (2nd ed.). São Paulo: WMF Martins Fontes.

Voet, M., \& De Wever, B. (2016). History teachers' conceptions of inquiry-based learning, beliefs about the nature of history, and their relation to the classroom context. Teaching and Teacher Education, 55, 57-67. https://doi.org/10.1016/j.tate.2015.12.008

Windschitl, M. (2002). Framing Constructivism in Practice as the Negotiation of Dilemmas: An Analysis of the Conceptual, Pedagogical, Cultural, and Political Challenges Facing Teachers. Review of Educational Research Summer, 72(2), 131-175. Retrieved from http://journals.sagepub.com/doi/pdf/10.3102/00346543072002131 


\section{Natália Ferreira Campos}

${ }^{\circ}$ http://orcid.org/0000-0002-9290-575X Universidade de São Paulo Programa de Pós-graduação Interunidades em Ensino de Ciências São Paulo, Brasil natafcampos@gmail.com

Daniela Lopes Scarpa

${ }^{\circledR}$ http://orcid.org/0000-0002-7720-7611 Universidade de São Paulo Instituto de Biociências Departamento de Ecologia São Paulo, Brasil dlscarpa@usp.br

Submetido em 18 de Abril de 2018 Aceito em 18 de Agosto de 2018 Publicado em 30 de Agosto de 2018 